\title{
Computer-aided Drug Designing of Ocimum basilicum Compounds as Therapeutic Agents Against RdRp of SARS-CoV2
}

\author{
Mehwish Shafiq $^{a}$, Rashid Saif ${ }^{b, c^{*}}$, Laraib Ali ${ }^{a}$, Tuba Ahmad $^{a}$, Anood Sohail $^{a}$ \\ ${ }^{a}$ Department of Biotechnology, Kinnaird College for Women, Lahore 54000, Pakistan; \\ ${ }^{\mathrm{b}}$ Institute of Biotechnology, Gulab Devi Educational Complex, Lahore 54000, Pakistan; \\ ${ }^{\mathrm{c}}$ Decode Genomics, Punjab University Employees Housing Scheme (II), Lahore, Pakistan \\ *Corresponding author: rashid.saif37@gmail.com
}

\begin{abstract}
The prevailing situation of the world is challenging due to COVID-19 pandemic that is caused by SARS-CoV2. To combat with this emerging pandemic by reducing disease severity and infection, the need of hour is to develop an effective vaccine and antiviral candidates as therapeutic agents against SARS-CoV2. This study was developed for the identification of potential anti-viral agents, from Ocimum basilicum against RdRp of SARS-CoV2. In this concern, nevadensin, ursolic acid, $\beta$-Sesquiphellandren, apigenin, nerolidol, nonyl acetate and geranyl acetate were screened out of fifty-seven compounds from Ocimum basilicum based on their best docking scores. The docking results were also compared with already clinically used drugs (Remdesivir and Ribavirin) against RdRp of SARS-CoV2. Molecular docking was performed using MOE software. The ADMET analysis and drug likeliness were also performed for all screened compounds by using admetSAR, pkCSM and SwissADME. Cumulatively, the optimum binding energies of screened compounds indicated their potential for drug development against SARS-CoV2. It appears promising that nevadensin exhibited a good docking score and high binding affinity towards RdRp of SARS-CoV2. Therefore, it may represent the potential to inhibit COVID-19. Hence, Ocimum basilicum nutraceuticals could be effective therapeutic candidates for the treatment and prevention of COVID-19.
\end{abstract}

Keywords: SARS-CoV-2; COVID-19; Ocimum basilicum; molecular docking; nevadensin. 


\section{Introduction:}

Coronavirus disease (COVID-19) is a communicable and life-threatening infection that is triggered by Severe Acute Respiratory Syndrome Coronavirus (SARS-CoV2) ${ }^{1}$. This virus is a single-stranded, positive-sense RNA enveloped and is transmissible in humans. The SARSCoV2 belongs to MERS and SARS family; all of these are beta coronaviruses and they have their origins in bats. This viral infection was initially reported in Wuhan, China ${ }^{2}$. COVID-19 has subsequently spread internationally. On March 11, the World Health Organization (WHO) stated the 2019-2020 novel coronavirus as a pandemic ${ }^{3}$. COVID-19 causes a respiratory infection through common symptoms like cough, fever, difficulty in breathing, muscle pain, diarrhea, sore throat and sputum production ${ }^{4}$. However, the majority of COVID-19 cases lead to pneumonia, diarrhea along with multiple organ damage ${ }^{5}$. Among all organs of the body, the lungs are the most affected organ with COVID-19 due to the presence of enzyme ACE2 in the alveolar cells of lungs, and the SARA-CoV2 virus has an affinity with this enzyme on the receptor-binding site. Due to the progress of the alveolar disease, respiratory failure occurs as follows with the death of patients ${ }^{6}$.

The SARS-CoV2 is a positive-sense, single-stranded RNA virus and its genome size varies from 29.8 to $29.9 \mathrm{~kb}^{7}$. The single virion (50-200 nanometer) comprises 4 different types of structural proteins. These structural proteins are identified as Spike protein (S), Envelope protein $(\mathrm{E})$, Membrane protein $(\mathrm{M})$ and Nucleocapsid protein $(\mathrm{N})$. These proteins are different from one another with respect to structure as well as function; the $\mathrm{N}$ nucleocapsid protein holds the viral genome and other S, E, and M proteins are responsible for the formation of the viral envelope ${ }^{8}$. Spike proteins help in the attachment of the virion with the surface membrane of the host cell. Spike glycoproteins give the virus a corona-like appearance that is vital for its pathogenicity. The SARA-CoV2 virus has a suitable affinity for angiotensin-converting enzyme 2 (ACE2) present on the receptors of living cells that virion uses as a mechanism for entry into a cell ${ }^{9}$.

Non-structural proteins occupy the two-third region of the genome of SARS-CoV2. Main proteases, RNA-Dependent RNA Polymerases and helicases are important non-structural proteins 10. RNA-Dependent RNA Polymerases are coded by the nsp12 gene. It is an important multisubunit enzymatic machinery in SARS-CoV2 that is involved in the replication and transcription 
processes in viral genomes ${ }^{11}$. Open reading frameworks ORF1a, ORF1b, and polyproteins (RdRp) along with nsp7 and nsp8 as cofactors are involved in RNA polymerization ${ }^{12}$. Catalytic domains and protein sequences of this enzyme are highly conserved, which could be a promising drug target for the development of a therapeutic approach against RdRp ${ }^{13}$.

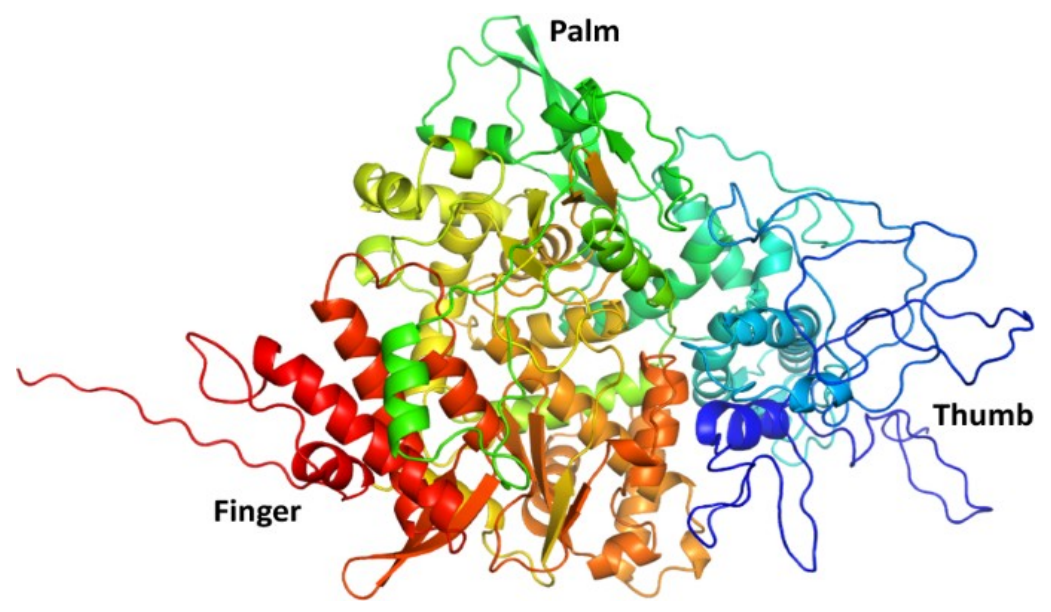

Figure 1.1 Structure of RNA-Dependent RNA Polymerases RdRp (PDB ID: 6M71)

Natural compounds from Eastern herbs show active defense mechanisms against various pathogens. In modern phytomedicine, herbs and medicinal plants are used as an alternative therapy due to the presence of active chemical constituents against a wide variety of viruses. In this pandemic situation, there is a need for the development of effective antiviral drugs against COVID-19. In the present study, the computational approach is used for screening compounds from Ocimum basilicum (Sweet basil) to check their potentiality for blocking the RdRp proteins of SARS-CoV2.

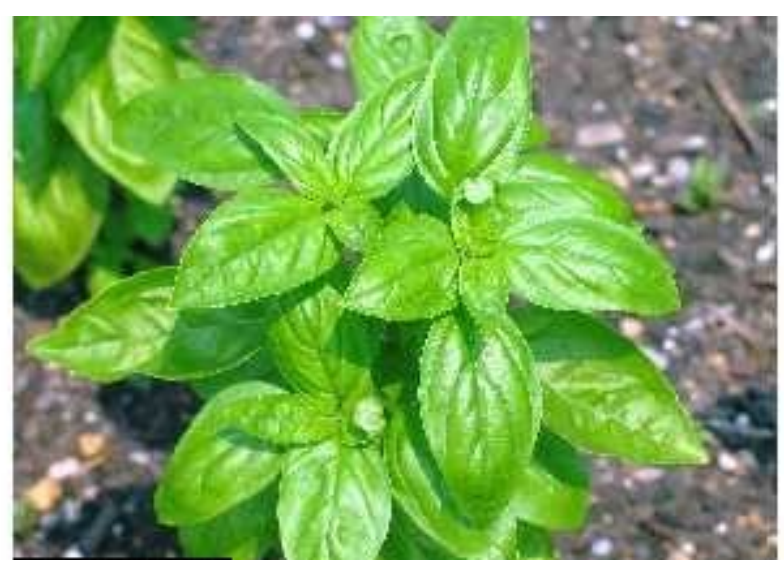


Figure 1.2 Ocimum basilicum (sweet basil) plant

Computer-aided in silico approach helps to facilitate and speed up the drug designing process in which different methods are used to identify novel therapeutic compounds.

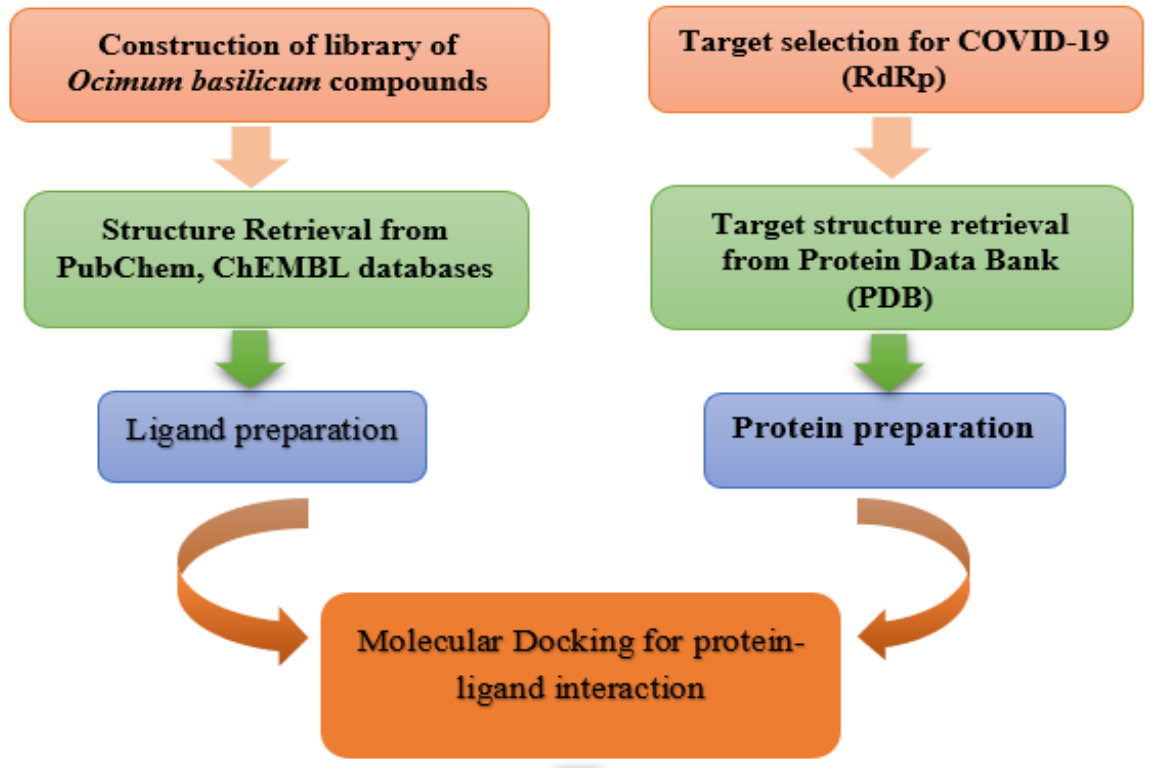

Figure 1.3: Comprehensive work stream of docking studies

\section{Material \& Methods:}

\subsection{Ocimum basilicum:}

Selection of medicinal plants for the discovery of potential antiviral drug agents was based on the presence of phytochemicals that are present in medicinal herbs. Here, we have selected the Ocimum basilicum which belongs to the Lamiaceae family. For a quite long time, it is being utilized in Asia as traditional medicine. It contains various compounds that have antiviral, antioxidant, antibacterial, antifungal, dermatologic, anticonvulsant and cytoprotective properties 15 .

\subsection{Target Protein of SARS-CoV2 and its reterival:}

RdRp is a key enzyme in SARS-CoV2. RdRp non-structural protein (nsp12) belongs to the class of nucleic acid polymerases. It is a central component of enzymatic machinery that is involved in the replication and transcription of the viral genome of SARS-CoV2 ${ }^{16}$. So, by targeting RdRp, 
viral replication can be halted. The structure of target protein RdRp was obtained from the Protein Data Bank (PDB ID: 6M71).

Table 2.2 Crystalline properties of RNA-dependent RNA-polymerase protein of coronavirus

\begin{tabular}{|c|c|c|c|c|c|c|c|}
\hline Enzyme & $\begin{array}{l}\text { PDB } \\
\text { Code }\end{array}$ & Classification & Organism & Resolution & Method & $\begin{array}{c}\text { Total } \\
\text { Structure } \\
\text { Weight } \\
\text { (DA) }\end{array}$ & Chain \\
\hline $\begin{array}{l}\text { SARS-CoV2 } \\
\text { RNA- } \\
\text { Dependent } \\
\text { RNA } \\
\text { Polymerases }\end{array}$ & $6 \mathrm{M} 71$ & $\begin{array}{l}\text { VIRAL } \\
\text { PROTEIN }\end{array}$ & $\begin{array}{l}\text { Severe acute } \\
\text { respiratory } \\
\text { syndrome } \\
\text { Coronavirus } \\
2\end{array}$ & $2.90 \AA$ & $\begin{array}{l}\text { ELECTRON } \\
\text { MICROSCOPY }\end{array}$ & $\begin{array}{c}161.22 \\
\mathrm{kDa}\end{array}$ & A \\
\hline
\end{tabular}

\subsection{Ligands Database reterival and their preparation:}

The structure of desired ligands was downloaded in SDF format from PubChem, Drug bank, ChEMBL and ChemSpider databases and sketched in the MOE interface by using Builder Mode. Canonical SMILES was used to build a 2D structure of ligands. After sketching the partial charges were added by using compute in MOE. Once charges were added, the prepared ligand was saved in the MDB file.

\subsection{Preparation of Target Protein:}

PDB is a source of our target protein, which was downloaded in the 6M71 PDB file. For the preparation of protein, following steps were performed: removal of inhibitors and repeated chains, correction of protein structure and 3D protonation of protein molecule. The repeated chains of RdRp were removed to avoid complications during docking.

\subsection{Molecular Docking:}

The molecular docking analysis was performed by MOE software. It was used to perform molecular docking for the protein-ligand interaction and drug-likeness analysis. MOE was also used for the visualization of results, modeling, and simulation of structures.

\subsection{Drug Likeness Analysis \& Toxicity Risk Prediction:}

After molecular docking, virtually screened chemical compounds from Ocimum basilicum were selected as potential drug agents that have strong inhibitory effects against RdRp target protein 
by using Lipinski's rule and AdmetSAR profiling. Lipinski's rule is also known as the rule of five (RO5). The assessment of absorption, digestion, metabolism, excretion and toxicity (ADMET) of screened compounds is essential in the drug development process for the evaluation of drug-likeness, level of toxicity, and pharmacokinetics ${ }^{17}$. SwissADME, pkCSM and admetSAR are online web tools that were used for AdmetSAR profiling to evaluate the ADMET physiochemical properties, toxicity, pharmacokinetics and drug-likeness.

\section{Results \& Discussion:}

\subsection{Molecular Docking Analysis:}

Molecular docking is an important tool to study interactions between protein and ligand at the atomic level. Here, we have investigated the binding efficiency of target protein RdRp of SARSCoV2 with different ligands using a computational approach in order to predict promising therapeutic drug molecules. Target protein RdRp was docked with 57 different compounds of Ocimum basilicum.

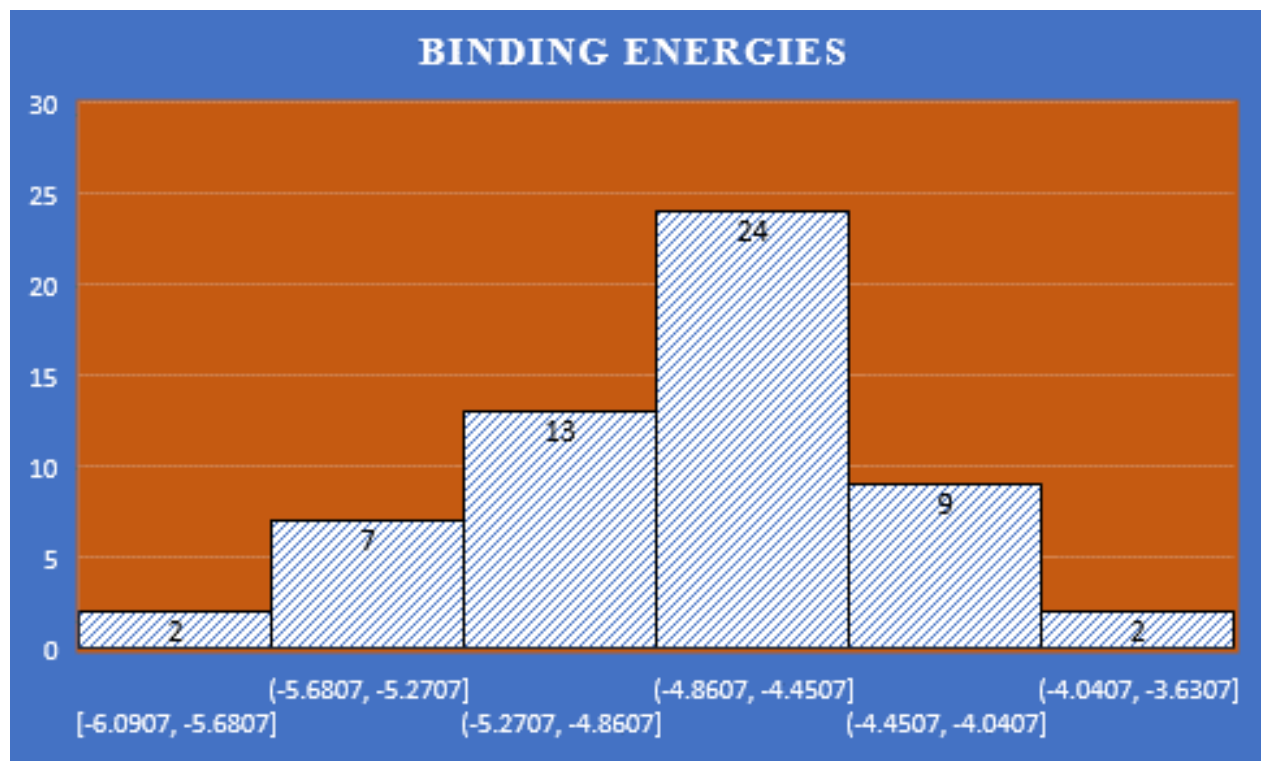

Figure 3.1 Histogram of molecular docking results of RdRp with several drug candidate compounds; $\mathrm{x}$-axis: binding energies $\Delta \mathrm{G}$ in $\mathrm{kcal} / \mathrm{mol}$; $\mathrm{y}$-axis: number of compounds

\subsection{Selected Compounds of Ocimum basilicum:}

After comprehensive analysis and comparison of the docking results of all compounds with control drugs, we have selected seven compounds of Ocimum basilicum based on their docking scores and molecular interactions of protein-ligand complexes. 
Table 3.2 Docking scores of selected compounds of Ocimum basilicum with target protein (PDB ID:6M71)

\begin{tabular}{|c|c|c|}
\hline Sr no. & Compounds & $\begin{array}{c}\text { Docking Scores } \\
\text { (Kcal/mol) }\end{array}$ \\
\hline 1. & Nevadensin & -6.0907 \\
\hline 2. & Ursolic acid & -5.9506 \\
\hline 3. & $\beta$ - Sesquiphellandren & -5.6538 \\
\hline 4. & Apigenin & -5.6119 \\
\hline 5. & Nerolidol & -5.5728 \\
\hline 6. & Nonyl acetate & -5.5153 \\
\hline 7. & Geranyl acetate & -5.4095 \\
\hline
\end{tabular}

Docking results ranked by binding energy $(\Delta G)$ values of different ligands are: nevadensin $>$ ursolic acid $>\beta$-Sesquiphellandren $>$ apigenin $>$ nerolidol $>$ nonyl acetate $>$ geranyl acetate with binding energies $-6.09,-5.95,-5.65,-5.61,-5.57,-5.51$ and $-5.40 \mathrm{kcal} / \mathrm{mol}$, respectively. Concerning docking analysis, nevadensin expressed high binding affinity towards RdRp polymerase of SARS-CoV2 than standard ribavirin drug $-6.09,-5.38 \mathrm{kcal} / \mathrm{mol}$, respectively. 


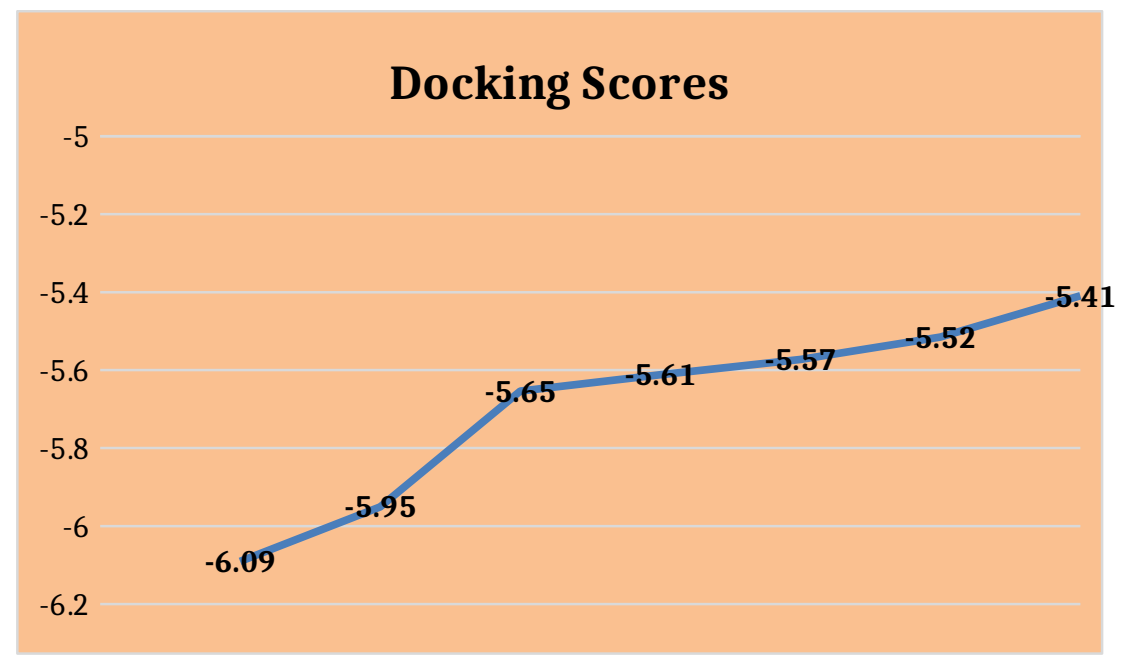

Figure 3.2 Graphical representation of docking scores

Table 3.3 2D interactions and 3D structures of selected protein-ligand complexes

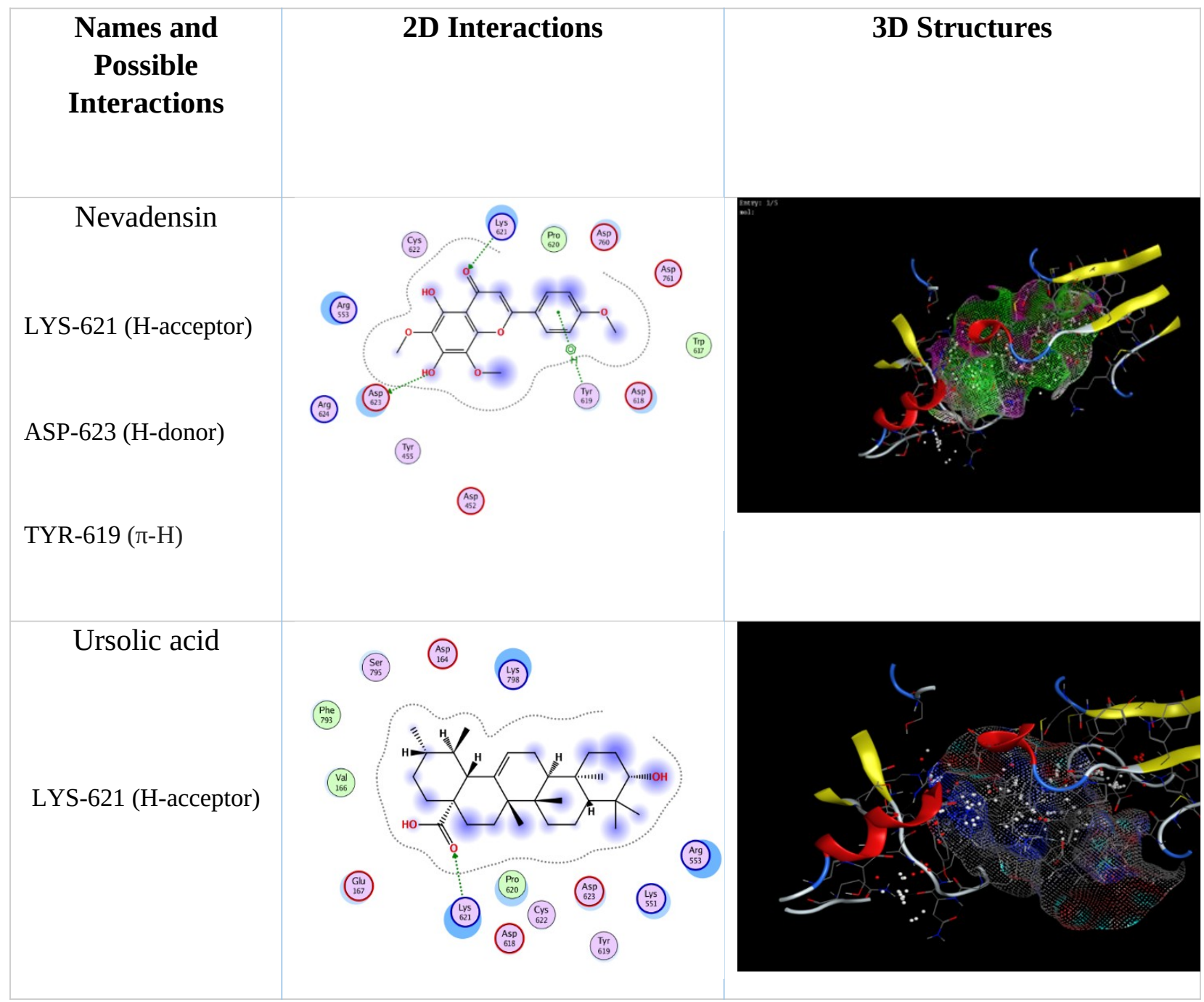




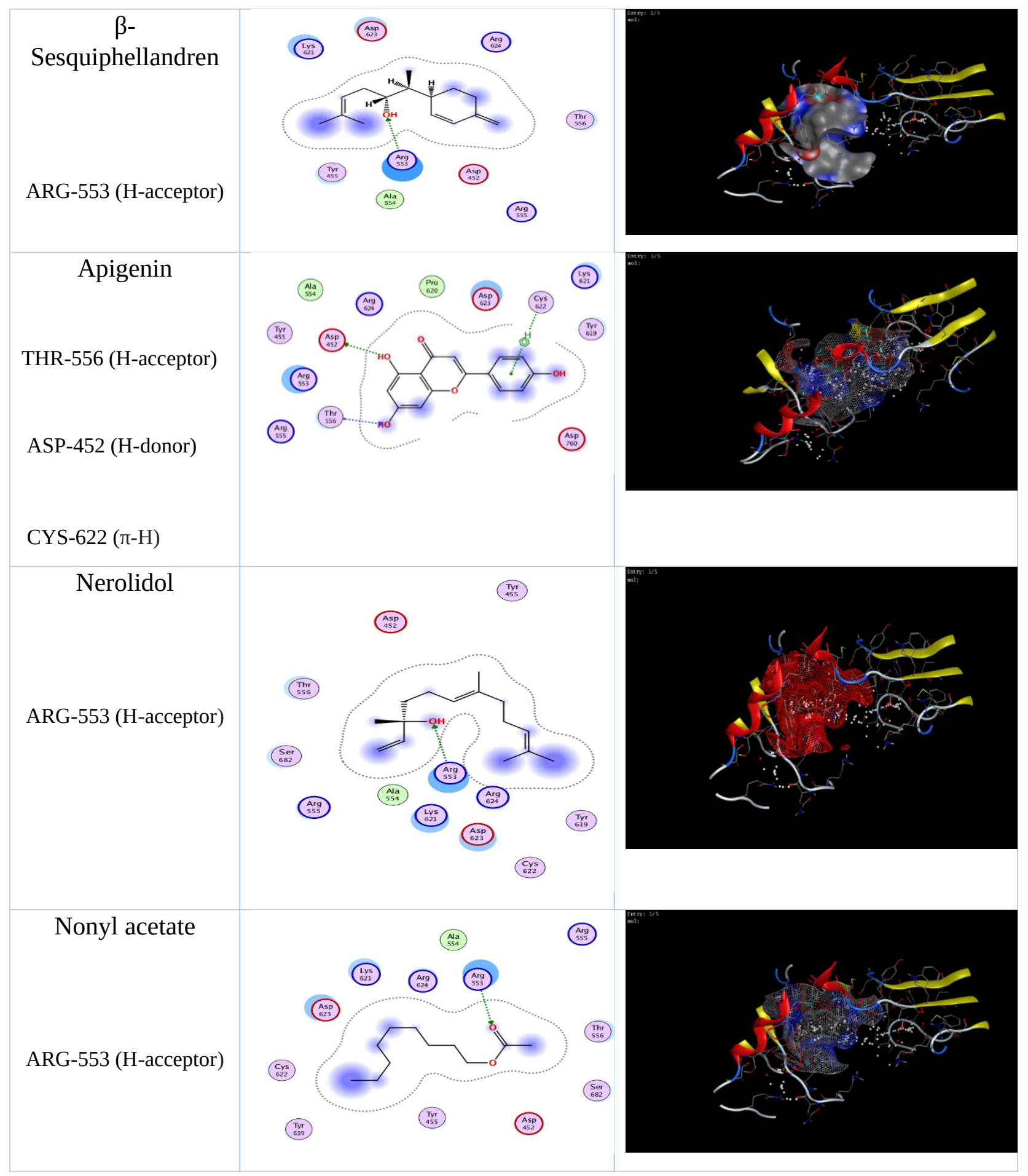




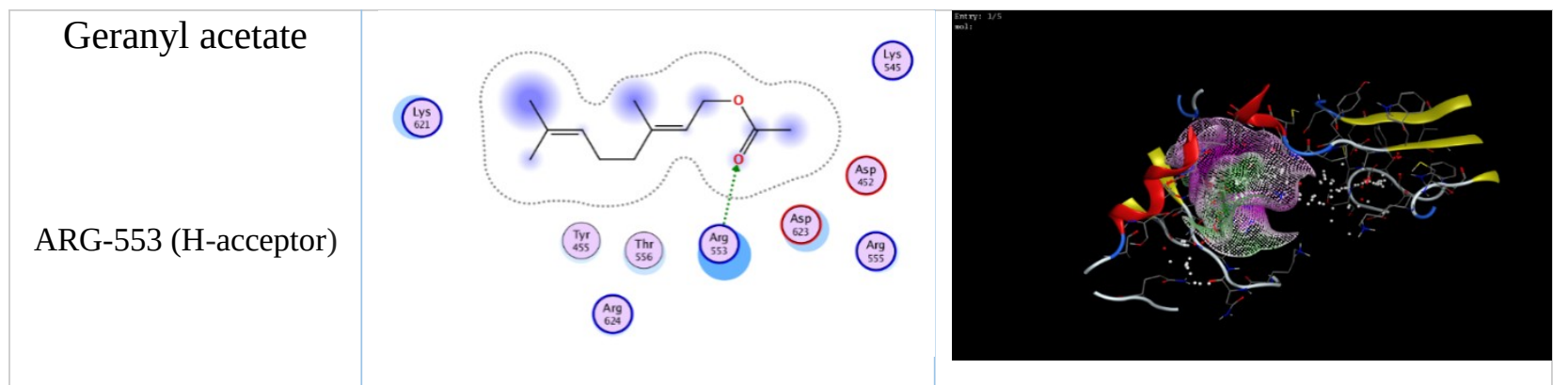

\subsection{Drug Likeness Analysis \& Toxicity Risk Prediction:}

Virtually screened chemical compounds from Ocimum basilicum were selected as potential drug agents that have strong inhibitory effects against RdRp target protein by using Lipinski's rule and AdmetSAR profiling. In the drug discovery process, bioavailability prediction and pharmacokinetics parameters are very important ${ }^{18}$.

Table 3.4 AdmetSAR profiling of Ocimum basilicum compounds according to Lipinski's rule of five

\begin{tabular}{|c|c|c|c|c|c|c|c|}
\hline Ligands & MW & $\begin{array}{c}\text { Donor } \\
\text { HB }\end{array}$ & $\begin{array}{c}\text { Acceptor } \\
\mathbf{( g / m o l )}\end{array}$ & $\begin{array}{c}\text { TPSA } \\
\mathbf{( A )}\end{array}$ & $\mathbf{L o g} \mathbf{P}$ & $\begin{array}{c}\text { Log } \\
\mathbf{S}\end{array}$ & Violation \\
\hline Nevadensin & 344.32 & 2 & 7 & $98.36 \AA^{2}$ & 2.90 & -4.03 & 0 \\
\hline Ursolic acid & 456.70 & 2 & 3 & $57.53 \AA^{2}$ & 7.09 & -4.38 & 1 \\
\hline $\begin{array}{c}(\mathbf{5}) \\
\beta-\end{array}$ & 220.35 & 1 & 1 & $20.23 \AA^{2}$ & 3.86 & -3.62 & 0 \\
\hline Sesquiphellandren & & & & & & & \\
\hline Apigenin & 270.24 & 3 & 5 & $90.90 \AA^{2}$ & 2.58 & -2.77 & 0 \\
\hline Nerolidol & 222.37 & 1 & 1 & $20.23 \AA^{2}$ & 4.40 & -3.80 & 0 \\
\hline Nonyl acetate & 186.29 & 0 & 2 & $26.30 \AA^{2}$ & 3.30 & -2.86 & 0 \\
\hline Geranyl acetate & 196.28 & 0 & 2 & $26.30 \AA^{2}$ & 3.24 & -3.21 & 0 \\
\hline
\end{tabular}


The drug likeliness properties of all selected compounds' molecular weight range from 186.29 to $344.32<500$ Daltons. Besides, number of hydrogen bond donors ( $\mathrm{NH}$ and $\mathrm{OH}$ ) less than 5 and numbers of hydrogen bond acceptors $(\mathrm{O}$ and $\mathrm{N})$ less than 10 were predicated in all selected compounds. Permeability possessions (log P) value less than 5 of all compounds were also studied except ursolic acid with $7.09 \log$ P and Topological Polar Surface Area (TPSA) of all ligands were less than $140 \AA^{2}$. It is an important component in computer-aided drug designing 19 .

Table 3.5 shows the bioavailability and synthetic accessibility scores of top screened molecules

\begin{tabular}{|c|c|c|c|}
\hline Ligands & Hit Structure & $\begin{array}{c}\text { Bioavailability } \\
\text { score }\end{array}$ & $\begin{array}{c}\text { Synthetic } \\
\text { accessibility score }\end{array}$ \\
\hline ChEBI ID: 7545 & \\
\hline Nevadensin & \\
\hline Ursolic acid & \\
\hline
\end{tabular}




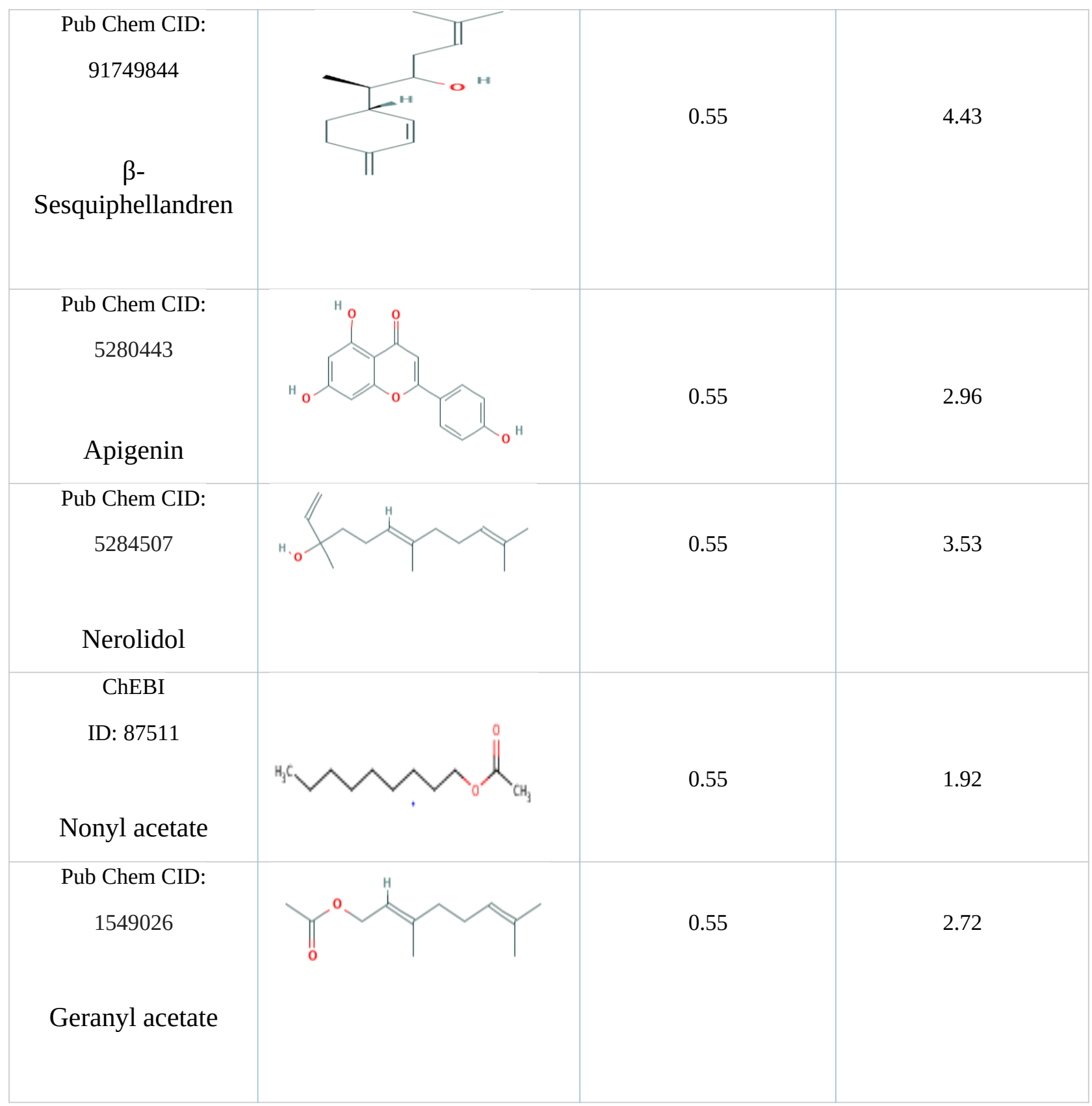

\section{Conclusions:}


The current study has provided a computer-aided drug designing (CADD) approach for potential drug agents from Ocimum basilicum against SARS-CoV2. The aim of this study was to examine the compounds of Ocimum basilicum against viral protein RdRp of SARS-CoV2, which is essential for viral replication. The main target protein RdRp was used to predict its molecular binding and docking score with different ligands of the selected plant. Therefore, the major seven compounds from Ocimum basilicum which gave the best lowest binding energies were selected. It appears promising that nevadensin exhibited a good docking score and high binding affinity with RdRp of SARS-CoV2. Hence, it may have the potential to inhibit COVID-19. Additionally, ursolic acid, $\beta$-Sesquiphellandren, apigenin, nerolidol, nonyl acetates and geranyl acetate seems to have the best potential to act as polymerase inhibitors of SARS-CoV2. Thus, these suggested therapeutic candidates as COVID-19 polymerase inhibitors need further investigations and clinical trials for their potential medicinal uses against SARS-CoV2.

Conflict of interest: The authors declare no conflict of interest.

\section{References:}

1. D. S. Hui, E. I. Azhar, T. A. Madani, F. Ntoumi, R. Kock, O. Dar, G. Ippolito, T. D. Mchugh, Z. A. Memish and C. Drosten, International Journal of Infectious Diseases 91, 264-266 (2020).

2. N. Chen, M. Zhou, X. Dong, J. Qu, F. Gong, Y. Han, Y. Qiu, J. Wang, Y. Liu and Y. Wei, The Lancet 395 (10223), 507-513 (2020).

3. G. H. Tison, R. Avram, P. Kuhar, S. Abreau, G. M. Marcus, M. J. Pletcher and J. E. Olgin, Annals of Internal Medicine (2020).

4. Y.-H. Jin, L. Cai, Z.-S. Cheng, H. Cheng, T. Deng, Y.-P. Fan, C. Fang, D. Huang, L.-Q. Huang and Q. Huang, Military Medical Research 7 (1), 4 (2020).

5. C.-C. Lai, T.-P. Shih, W.-C. Ko, H.-J. Tang and P.-R. Hsueh, International journal of antimicrobial agents, 105924 (2020).

6. Y. Yong, X. Mo, Y. Hu, X. Qi, F. Jiang, Z. Jiang and S. Tong, Pediatrics (2020).

7. R. A. Khailany, M. Safdar and M. Ozaslan, Gene reports, 100682 (2020).

8. I. Astuti, Diabetes \& Metabolic Syndrome: Clinical Research \& Reviews (2020).

9. A. C. Walls, Y.-J. Park, M. A. Tortorici, A. Wall, A. T. McGuire and D. Veesler, Cell (2020).

10. P. Chellapandi and S. Saranya, Medicinal Chemistry Research, 1-15 (2020).

11. P. Sargunam and S. Sridharan, (2020).

12. P.-H. Tsai, M.-L. Wang, D.-M. Yang, K.-H. Liang, S.-J. Chou, S.-H. Chiou, T.-H. Lin, C.-T. Wang and T.-J. Chang, Journal of the Chinese Medical Association 83 (8), 725-732 (2020). 
13. J. Huang, W. Song, H. Huang and Q. Sun, Journal of Clinical Medicine 9 (4), 1131 (2020).

14. A. F. Ahmed, F. A. Attia, Z. Liu, C. Li, J. Wei and W. Kang, Food Science and Human Wellness 8 (3), 299-305 (2019).

15. S. Rubab, I. Hussain, B. A. K. A. A. Unar, K. A. Abbas, Z. H. Khichi, M. Khan, S. Khanum and K. U. R. H. Khan, Journal of Islamic International Medical College 12 (1), 57-69 (2017).

16. Y. Gao, L. Yan, Y. Huang, F. Liu, Y. Zhao, L. Cao, T. Wang, Q. Sun, Z. Ming and L. Zhang, Science 368 (6492), 779-782 (2020).

17. V. K. Maurya, S. Kumar, A. K. Prasad, M. L. Bhatt and S. K. Saxena, VirusDisease, 1-15 (2020).

18. B. J. Aungst, Journal of pharmaceutical sciences 106 (4), 921-929 (2017).

19. A. Daina, O. Michielin and V. Zoete, Scientific reports 7, 42717 (2017). 